\title{
Cooperação judicial internacional pela via do auxílio direto no combate à subtração internacional de menores no Brasil e na Colômbia
}

\author{
INTERNATIONAL JUDICIAL COOPERATION BY \\ MEANS OF DIRECT AID IN THE FIGHT AGAINST \\ INTERNATIONAL ABDUCTION OF CHILDREN IN \\ Brazil and Colombia
}

\author{
* Alessandra Mizuta \\ ** Carla Evelise Justino Hendges
}

* Discente do programa de Doutorado da Pontifícia Universidade Católica do Rio Grande do Sul. Docente da Universidade Luterana do Brasil. Coordenadora Adjunta do curso de Direito ULBRA/Canoas Doutoranda do PPGD PUCRS. E-mail: alessandra.mizuta@gmail.com

** Doutoranda em Direito pela PUC/RS Brasil. Juíza Federal. Mestre em Direito pela UNISC. Professora convidada em cursos de pós-graduação lato sensu. E-mail: chendges@terra.com.br
Resumo: O presente artigo aborda o tema da cooperação judiciária internacional pela via do auxílio direto. Indaga-se do impacto da globalização em relação ao Estado, ao direito e aos sistemas jurídicos. Contextualizam-se o déficit de efetividade dos direitos e a crise do processo. Situa-se a cooperação judiciária internacional como um instrumento apto a promover uma integração dos diferentes sistemas judiciários, necessária em um mundo complexo e interligado no qual se esvanecem as fronteiras estatais. Dentre as modalidades de cooperação judiciária internacional, destaca-se o auxílio direto como um mecanismo de cooperação entre os Estados, com viés desburocratizante, contribuindo para uma prestação jurisdicional mais ágil e para a concretização dos direitos também no plano internacional. Um dos instrumentos internacionais que prevê a cooperação via auxilio direto é a Convenção da Haia sobre sequestro internacional de menores, de 1980. Examinam-se de forma comparativa os procedimentos de cooperação judiciária nos aspectos civis relativos ao sequestro de crianças no Brasil e na Colômbia.

Palavras-chave: Cooperação jurídica internacional; Relativização da soberania; Auxílio direto; Globalização; Sequestro internacional de menores; Convenção da Haia de 1980.

Abstract: This paper addresses the issue of international judicial cooperation by the direct assistance. It reflects on the impact of globalization on the state, the law and the legal systems. Contextualize the reduction of the effectiveness of the rights and the crisis of the process. Adresses the international judicial cooperation as a tool to promote integration of various judicial systems, necessary in a complex and interconnected world in 
which state borders vanish. Among the modalities of international judicial cooperation, there is the direct assistance as a mechanism for cooperation among states, as a less bureaucratic vies, contributing to a more agile adjudication for the achievement of the rights also internationally. One of the international instruments that provide for cooperation by the direct assistance the Hague Convention on international abduction of minors, 1980. Will be examined comparatively procedures for judicial cooperation in civil aspects of child abduction in Brazil and Colombia.

Keywords: International juridical cooperation; Relativization of sovereignty; Direct assistance; Globalization; International child abduction; 1980 Hague Convention. 


\section{INTRODUÇÃO}

Em um momento histórico no qual um dos maiores desafios das sociedades contemporâneas é assegurar a efetividade dos direitos fundamentais, constatase que os sistemas jurídicos precisam se adaptar para fazer frente aos desafios trazidos pela globalização.

Diante do fenômeno da mundialização das relações sociais, esvanecemse as fronteiras estatais, sobrepassadas pelo tráfego internacional cada vez mais intenso de pessoas, bens e negócios jurídicos. Em decorrência, surgem novas lides regionais, internacionais, supranacionais, reclamando solução judicial.

Para tais controvérsias transnacionais, a jurisdição e o processo civil, tal como tradicionalmente concebidos, vinculados à soberania e limitados ao espaço estatal, não estão aptos a dar solução adequada. A presença do elemento de alteridade internacional em um processo judicial interfere no acesso à justiça, pela formalidade e dificuldade dos procedimentos, atrasando a prestação jurisdicional e, ao fim e ao cabo, influindo na falta de efetividade da jurisdição e na própria concretização dos direitos.

Essa preocupação levou a que venham sendo aprofundadas as discussões sobre o tema da cooperação judicial internacional, ou cooperação jurídica internacional, compreendida como prestação de auxílio recíproco entre os diferentes Estados para a execução de medidas processuais.

Nos últimos anos, vêm sendo concebidos novos instrumentos jurídicos de cooperação, menos formalistas e rígidos, para enfrentar a nova dinâmica de relações sociais em rápida e constante transformação.

No presente trabalho, buscar-se-á analisar o auxílio direto, o mais inovador e menos conhecido dos instrumentos jurídicos de cooperação jurídica internacional, sobre o qual constam poucos estudos a respeito da aplicação no processo civil. Buscar-se-á estabelecer uma análise comparativa entre a forma de cooperação por auxílio direito nos sistemas brasileiro e colombiano, em relação ao procedimento adotado nos casos de sequestro internacional de menores, com base na Convenção da Haia.

Para tanto, inicia-se com uma reflexão sobre os efeitos da globalização frente à soberania do Estado, buscando contextualizar a cooperação jurídica internacional como mecanismo garantidor do direito fundamental de acesso à justiça. A seguir, examina-se o tema da cooperação judiciária internacional em matéria civil pela via do auxílio direto, a partir de uma síntese evolutiva do instituto, buscando indagar da sua compatibilidade com o ordenamento jurídico constitucional e traçar as linhas básicas do procedimento a ser adotado. $\mathrm{Na}$ 
terceira seção, serão analisados os sistemas adotados no Brasil e na Colômbia no sequestro intraparental, indagando-se da forma de efetivação da cooperação judicial pela via do auxílio direto em ambos os países. Por fim, apresentar-se-ão algumas considerações finais sobre o tema.

\section{AS RELAÇÕES JURÍDICAS ALÉM DAS FRONTEIRAS DA NAÇÃO SỎBERANA}

Para tratar a respeito da cooperação jurídica internacional, é imprescindível bordar primeiro o fenômeno que torna cada vez mais necessária a comunicação de diferentes nações igualmente soberanas.

Conforme observado por Luhmann (1997), não parece haver dúvidas quanto ao fato de se viver uma realidade dentro de uma sociedade global. Não obstante seja natural vermos os Estados como sistemas sociais mais ou menos bem definidos, não se pode deixar de analisar a globalização como uma ampliação destes sistemas sociais.

Embora se possa fazer referência a uma comunidade global desde tempos remotos, mencionando como exemplo o comércio no Mediterrâneo desde os tempos dos fenícios, o avanço da globalização certamente se acelerou nas últimas décadas, com a revolução tecnológica, notadamente nas áreas de comunicação, transporte e na verdadeira explosão da rede mundial de computadores.

A economia mundial vem se integrando de forma acentuada, em especial a partir da década de 80, espalhando seus reflexos por todos os países ao redor do mundo, seja em maior ou menor grau.

Para Anthony Giddens (1991) a globalização fez com que o estudo das cidades necessariamente leve em consideração o que ocorre em sua vizinhança, pois ainda que ocorridos a milhas de distância, os eventos influenciarão todo o seu arredor em decorrência da intensificação das relações sociais, que tomaram proporções em escala mundial.

Cada vez mais, os efeitos dos eventos transpõem barreiras geográficas e políticas e, em especial, os eventos econômicos não encontram muita resistência para surtir efeitos praticamente de forma imediata em todo o resto do mundo.

Em decorrência da intensificação do comercio internacional, o Direito Internacional Privado tem se dedicado a promover estudos e elaborar ferramentas para a sua uniformização.

Para minimizar a barreira jurídica existente (em razão da diversificação normativa) os organismos internacionais têm se concentrado em formar regras factíveis e de grande aceitabilidade. 
Em se tratando de direitos patrimoniais disponíveis, os usos e costumes (lex mercatoria) já se mostravam suficientes para possibilitar a regulamentação das relações em diferentes fronteiras.

Ole Lando (1991) cita como fonte da lex mercatoria as leis uniformes, criadas e adotadas por países que participam do movimento de uniformização das leis do comércio internacional, mencionando como exemplo a Lei Uniforme sobre a Venda de Bens de 1964.

As convenções, quando ratificadas pelos países, tornam-se legalmente vinculativas, o que possibilita um maior grau de uniformização. São exemplos: o Institut pour l'Unification du Droit (UNIDROIT), a Convenção de Viena, de 1980, a United Nations Comission on International Trade Law (UNICITRAL).

Por outro lado, as Leis Uniformes seriam meras orientações para as legislações nacionais, não havendo um comando imperativo, o que possibilita tão somente a harmonização das regras do comércio internacional e não sua uniformização.

Entretanto, enquanto o maior desafio no direito internacional privado é o da uniformização das leis a fim de garantir a segurança jurídica das relações que possuem como objeto direitos disponíveis, em se tratando de direitos indisponíveis o debate tem outros contornos.

Em decorrência das barbáries da Segunda Guerra Mundial, é criada a Organização das Nações Unidas (1945), que em 1948 editou a Declaração Universal dos Direitos Humanos (1948). Não obstante sua influencia e importância histórica, não possuía efeito vinculante, mas serviu de base para importantes tratados, estes sim com força legal. Entre eles o Pacto Internacional sobre Direitos Civis e Políticos (1966) e o Pacto Internacional dos Direitos Econômicos, Sociais e Culturais (1966).

Assim, ainda que os organismos internacionais venham reunindo esforços para que o homem possa ter sua vida em liberdade, igualdade e dignidade (assegurados os direitos civis, políticos, econômicos, sociais e coletivos), a efetividade dos direitos humanos merece um olhar mais atento.

Somado à necessidade de assegurar o alcance do homem aos direitos prestacionais do Estado, encontra-se o desafio de lidar com a expansão das relações além das fronteiras da soberania das nações. Mas diferentemente das relações privadas que podem contar com a escolha da legislação aplicável, ou até mesmo por métodos alternativos de solução de conflitos, as questões de direito público permanecem vinculadas à atuação do Estado. 


\subsection{Soberania: Superação do Legalismo Positivista e Envolvimento dos Poderes com as Relações Internacionalizadas}

Para que se compreenda a tão necessária cooperação internacional, fazse necessário antes compreender o que representa a soberania para o Estado e de que forma a globalização interferiu em sua tradicional noção de independência, indivisibilidade e completude.

Logo no artigo $1^{\circ}$, inciso I, da Constituição Federal, a Carta Magna prevê a soberania como um dos fundamentos da República Federativa do Brasil:

Art. $1^{\circ}$ A República Federativa do Brasil, formada pela união indissolúvel dos Estados e Municípios e do Distrito Federal, constitui-se em Estado Democrático de Direito e tem como fundamentos:

I - a soberania;

A ênfase na soberania indica a autonomia do Brasil em relação a todos os demais países, a qualquer poder estrangeiro (nação ou organização internacional), assinala a ausência de intenção de se sujeitar a interferências externas em decorrência da independência a ela agregada.

Sendo a soberania una e indivisível, por ter escolhido o modelo político democrático, o Brasil confere diferentes atribuições às esferas de Poder, dividindo-as em Executivo, Legislativo e Judiciário.

Uma noção importante e destacada por Facchini Neto (2007, p. 297), é a da "superação do legalismo positivista, que identificava no legislador a verdadeira locomotiva do Direito, vendo no Juiz a figura montesquiana de mera 'boca da lei"”.

Ao tratar acerca do Neoprocessualismo ${ }^{1}$, Fredie Didier Junior enfatiza a evolução e importância da atuação do operador do direito na aplicação da norma.

\footnotetext{
Fredie Didier Jresclarece que após a II Guerra Mundial, em razão das barbáries as quais o homem foi submetido, houve uma mobilização internacional para promover a proteção aos direitos humanos. Em âmbito nacional, foram promulgadas Constituições de caráter social e democrático, em que ocorreu a positivação de princípios jurídicos com ênfase nos direitos fundamentais. A Constituição deixa de ser uma mera carta de intenções políticas e torna-se um sistema de preceitos vinculantes e passa a exercer influência direta sobre todas as demais áreas do direito (Neoconstitucionalismo). Este movimento possui como características: (1) o reconhecimento da força normativa da Constituição, tornando-se a carta magna o principal veículo normativo no sistema jurídico; (2) o desenvolvimento da teoria dos princípios, reconhecendo-lhes eficácia normativa; (3) transformação da hermenêutica jurídica, privilegiando a função jurisdicional e sua interpretação dos textos normativos e (4) a expansão e consagração dos direitos fundamentais. O Direito Processual Civil não foge a esta regra e sofre influência direta do Neoconstitucionalismo, movimento ao qual o autor chama de Neoprocessualismo.
} 
Neste particular, a interpretação da norma passa a ter um papel fundamental para o desenvolvimento do Direito:

Transformação da hermenêutica jurídica, com o reconhecimento do papel criativo e normativo da atividade jurisdicional: a função jurisdicional passa a ser encarada como uma função essencial ao desenvolvimento do Direito, seja pela estipulação da norma jurídica do caso concreto, seja pela interpretação dos textos normativos, [...] Expande-se, ainda, a técnica legislativa das cláusulas gerais, que exigem do órgão jurisdicional um papel ainda mais ativo na criação do Direito (DIDIER JUNIOR, 2010, p. 259).

Desta forma, percebe-se que a atividade legislativa não é o suficiente para assegurar o alcance ao Direito, passando o Judiciário a exercer papel fundamental para a sua efetivação.

Entretanto, a soberania que pretensamente seria uma barreira às interferências externas em decorrência da autonomia plena do Estado, muito mais do que proteger das ingerências internacionais, acabaria servindo de empecilho para a concretização de direitos individuais.

A transformação das relações sociais demonstraram que as fronteiras, ao mesmo tempo que protegem, poderiam limitam o alcance à efetivação das pretensões do cidadão.

Neste particular, a quebra de paradigma aconteceu com a expansão da globalização, que ultrapassou o setor econômico e avançou sobre todas as demais áreas de conhecimento. Enquanto o direito internacional privado vem há tempos enfrentando o tema para garantir maior segurança jurídica ao comércio internacional, no mesmo sentido o direito internacional público também vem enfrentando a necessidade de participar dos debates, consolidados em tratados e acordos internacionais em torno (em especial) dos direitos humanos.

Em razão das transformações advindas da globalização, Jacques Chevallier (2013) aponta a crise no modelo de Estado, Direito ou política estabelecidos na modernidade. O advento dos novos paradigmas que acompanharam a complexidade das relações, compostas por indeterminação e incertezas, demonstraram que fincar as bases na razão ou simplicidade não era mais o suficiente para solucionar os atuais conflitos.

A porosidade das delimitações do Estado traz como reflexo a modificação nas tradicionais concepções de soberania e das fronteiras físicas, o que torna necessárias as trocas internacionais e traz como consequência a relativização da soberania. 
Contraditoriamente, ao invés de a crise da modernidade jurídica significar a morte do direito, anuncia e prepara para uma nova fase de desenvolvimento, em que busca privilegiar os equilíbrios sociais em contrapartida à autonomia dos atores sociais.

Mas enquanto o legislativo e o executivo avançaram com a evolução das relações sociais, reunindo esforços pela cooperação internacional enquanto participam das convenções e negociações internacionais, integrando as políticas públicas em prol da defesa dos direitos humanos, o poder judiciário vinha caminhando de forma mais tímida.

Em linhas gerais, a atuação do judiciário envolvendo questões que ultrapassem fronteiras, ocorre de forma burocrática, a exemplo do procedimento envolvendo diligências via carta rogatória. Entretanto, o auxílio direto acena uma intenção de promover uma maior integração jurídica internacional do poder judiciário.

\subsection{Os Efeitos da Globalização Sobre a Soberania do Estado: Cooperação Jurídica Internacional}

No intuito de promover a pacificação social, mantendo o bem estar comum, o Estado reclamou para si o monopólio da jurisdição e "diante da proibição da autotutela, ofertou-se àquele que não podia mais realizar o seu interesse através da própria força o direito de recorrer à justiça, ou o direito de ação" (MARINONI; ARENHART, 2014, p. 31).

Desta forma, passa a ser um poder/dever do Estado sub-rogar-se na vontade das partes, garantindo a efetividade das leis, aplicando-as no caso concreto para solucionar os conflitos trazidos pelos particulares ou por entes públicos. Some-se a isto a missão de ser o guardião dos Diretos Fundamentais, que legitima e limita a atuação do Estado.

Assim, sempre que se faça necessária a concretização da ordem jurídica (não ocorrendo esta de forma voluntária), a intervenção do Estado ocorrerá por meio do Poder Judiciário.

Neste particular, relevante mencionar o princípio constitucional da inafastabilidade do controle judicial, incorporado pelo sistema constitucional vigente pelo artigo 5, inciso XXXV, da Constituição Federal, segundo o qual "a lei não excluirá da apreciação do Poder Judiciário lesão ou ameaça a direito". Se por um lado garantiu o livre acesso ao Judiciário, tendo a parte direito a ver apreciadas pelo juízo competente as suas razões, por outro, impõe como dever do Estado a fundamentação das decisões que lhes negam conhecimento. 
Cabe frisar que a função judiciária ou jurisdicional é a forma de exercício da soberania realizada pelo Poder Judiciário, assim como os demais poderes a exercem no âmbito de suas respectivas atribuições.

Mesmo sendo a jurisdição o exercício da soberania, sofre ela limitações. Em linhas gerais, os limites internacionais da jurisdição poderiam ser apontados como decorrentes da existência de outros Estados igualmente soberanos, o respeito às convenções internacionais e por razões de interesse do próprio Estado.

Ocorre que o exercício da jurisdição, tal como conhecido classicamente, não tem mais sido suficiente para responder às demandas dos jurisdicionados, porque os conflitos ganharam outros contornos. Grande parte do aumento da complexidade das demandas se deve aos efeitos da globalização.

Embora o direito seja visto como prerrogativa de Estados soberanos, "as pessoas e suas relações jurídicas cada vez mais se deslocam no espaço, sobretudo no mundo globalizado atual.” (GAMA JUNIOR, 2006, p. 2)

O fenômeno da globalização fez surgir uma nova sociedade (sociedade mundial), que apresenta conflitos que ultrapassam as barreiras das fronteiras geográficas politicamente estabelecidas.

Os usos e costumes não são mais regionalizados, mas mundializados, fazendo com que a soberania venha a sofrer uma relativização.

Enquanto de um lado as políticas voltadas ao direito internacional privado buscam a uniformização das normas que regulamentam as relações comerciais, por outro, o direito internacional público busca (entre outras coisas) assegurar a efetividade dos direitos humanos garantindo que a soberania dos Estados não gere barreiras intransponíveis para a sua concretização.

No mesmo sentido, em decorrência da globalização, o judiciário brasileiro tenta se adequar às transformações sociais (influenciadas pela cultura e comportamentos globalizados), ajustando seus conceitos.

Para Anderson Teixeira o componente introduzido pela globalização é um agente ativo, que embora não se mostre presente de forma clara, exerce influencia a tal ponto que a integração econômica-social ultrapassa os limites dos estados-nação e de toda a estrutura político-jurídica:

A informatização das relações sociais e econômicas, ocorrida nas últimas duas décadas do século passado, permitiu que a "sociedade global" fosse finalmente percebida - ainda que de modo incipiente e controverso - no mundo: o fato de que qualquer indivíduo, em qualquer lugar do mundo, possa entrar em contato e estabelecer relações interpessoais com qualquer 
outro indivíduo do mundo, estabelece um ponto de referência para o real surgimento da globalização (TEIXEIRA, 2011, p. 4).

Ainda de acordo com o autor, diante disto, instala-se a "crise do Estado", já que este não possui mais a capacidade de conservar uma unidade interna própria e nem de impor sua soberania externa no domínio econômico.

A independência garantida pela soberania já não surte mais os mesmos efeitos para o Estado, que agora sofre influências externas significativas, as quais a submissão torna-se inevitável, diante da atual realidade globalizada.

A noção básica de Estado soberano deve agora abarcar além da administração das tensões internas, também os desdobramentos internacionais, a tal ponto que, somadas às competências nacionais, agrupam-se as supranacionais, tornando inevitável a cooperação internacional.

Diante deste cenário, a tutela interna já não se mostra mais suficiente para assegurar a efetividade dos direitos fundamentais, já que as relações se expandiram a ponto de envolver a necessidade de interação além das fronteiras geográficas.

Conforme já mencionado, o Poder Judiciário abandonou seu papel coadjuvante de mero aplicador da norma e passou a contribuir para o efetivo acesso às prestações do Estado, o que no atual cenário mundializado, para que ocorra de forma plena, depende de cooperação de outros Estados:

Os juízes de hoje começam a ensaiar a possibilidade de serem porta-vozes não só da segurança dos que já têm, mas também da esperança dos muitos que ainda não têm, e que vêem no Judiciário uma possibilidade de acesso a certos direitos a prestação do Estado, enquanto cidadãos, e de fazer respeitar, pela sociedade, sua dignidade enquanto seres humanos (FACCHINI NETO, 2007, p. 298).

É necessário, como bem explana Peter Häberle, pensar em um Estado cooperativo e orientado pela solidariedade, aberto a outras ordens jurídicas:

Estado Constitucional Cooperativo é o Estado que justamente encontra a sua identidade também no Direito Internacional, no entrelaçamento das relações internacionais e supranacionais, na percepção da cooperação e responsabilidade internacional, assim como no campo da solidariedade, correspondendo, com isso, à necessidade internacional de políticas de paz. [...] O Estado Constitucional cooperativo trata, ativamente, da questão de outros Estados, de instituições internacionais e supranacionais e dos 
'cidadãos estrangeiros': sua 'abertura ao meio' é uma abertura ao mundo. (HÄBERLE, 2007, p. 6-7, grifo nosso).

Como assevera Mireille Delmas-Marty (2013), em uma sociedade mundializada e marcada pela predominância dos interesses das empresas transnacionais dotadas de mobilidade e plurilocalizadas, somente um sistema cooperativo de responsabilidade compartilhada entre as nações lograria assegurar a sindicabilidade judicial (justiciabilité) dos direitos fundamentais individuais e sociais. Para a mesma autora, a garantia da adequada proteção dos direitos demanda que os sistemas jurídicos sejam dotados de instrumentos capazes de reforçar a transparência das operações, facilitar a identificação dos responsáveis e possibilitar a imposição da adequada punição.

Nesse contexto, a cooperação jurídica internacional desempenha um importante papel de interligação cooperativa entre os diferentes sistemas jurídicos com vista à solução dos conflitos com elementos de cunho regional, transnacional e internacional. Se a concepção de uma ordem jurídica mundial cosmopolita ainda é uma utopia, ao menos a cooperação jurídica entre os aparatos judiciários dos diferentes Estados representa uma aproximação entre os diferentes sistemas, que se reforçam e reciprocamente aprimoram a prestação jurisdicional. Mais do que um mero ato de cortesia internacional, a cooperação constitui um dever necessário à garantia da efetividade dos direitos.

\section{COOPERAÇÃO JURÍDICA INTERNACIONAL PELA VIA DO AUXÍLIO DIRETO EM MATÉRIA CÍVEL}

\subsection{Aspectos Gerais da Cooperação Judicial Internacional Via Auxílio Direto}

As formas tradicionais de cooperação judiciária internacional constituíamse procedimentos burocráticos, complexos e morosos. A evolução histórica da cooperação jurídica internacional revela um incremento crescente da cooperação nas últimas décadas, com a busca de superação das limitações dos mecanismos tradicionais. Tem havido ampliação das fontes normativas da cooperação e dos espaços de sua consolidação, envolvendo questões fronteiriças, bilaterais, regionais, continentais ou mundiais.

Buscando adequar-se às necessidades de um mundo em rápida transformação, vem sendo concebidas várias formas de assistência recíproca, 
tanto nas demandas criminais quanto nas cíveis, nos mais variados tipos e graus de interação nos diferentes contextos internacionais, concertadas mediante uma multiplicidade de acordos multilaterais, bilaterais ou regionais. Como, a respeito, salienta Zavascki,

[...] inúmeros acordos e tratados celebrados em tempos recentes, em âmbito bilateral e multilateral, dos quais o Brasil também é signatário, buscaram instituir um novo padrão de cooperação, mediante criação de instrumentos mais compatíveis com as exigências dos novos tempos. Construiu-se, assim, um sistema de cooperação jurídica em que os instrumentos tradicionais, notadamente o das cartas rogatórias, passaram a conviver com formas mais modernas, instituídas por fontes normativas de direito público internacional (ZAVASCKI, 2010, p. 9).

Analisando o incremento dos mecanismos de cooperação e o surgimento de diversas formas de interação entre os juízes de diferentes países, Allard e Garapon (2005, p. 38) referem o surgimento de relações que denominam de "comércio de juízes" e que vão desde a troca de informações e experiências até o compartilhamento de jurisprudências, tudo porque "é necessário acompanhar as evoluções do mundo e adoptar um direito mais móvel quando os objectos também o são. O direito acompanha o que é transfronteiriço por natureza".

Acerca das múltiplas formas e graus que a integração entre os diferentes órgãos jurisdicionais pode assumir, vale mencionar a construção de Slaughter (1994), segundo a qual a comunicação entre os juízes pode variar extraordinariamente em relação à forma de comunicação, à função e aos graus de engajamento recíproco; poderá ocorrer de forma direta ou intermediada, individualmente ou por redes de cooperação, bem como entre órgãos jurisdicionais de diferentes estados ou entre estes e cortes supranacionais.

O auxílio direto, ou assistência direta, constitui um desses novos mecanismos de cooperação judiciária internacional ${ }^{2}$. A expressão não é unívoca, podendo ser compreendida de uma forma ampla, abrangendo tanto atos jurisdicionais como providências de natureza administrativa, ou mais restrita, abrangendo apenas a cooperação entre órgãos jurisdicionais. Caracteriza-se

\footnotetext{
${ }^{2}$ A abordagem desse trabalho se direciona à cooperação via auxílio direto entre os órgãos jurisdicionais dos diferentes países, sem olvidar que há formas de cooperação internacional por auxílio direto entre órgãos administrativos de diferentes estados e também outras modalidades de assistência judiciária em sentido amplo, não estritamente jurisdicionais, inclusive pré-processuais, dentre as quais se incluem as atividades preventivas, fiscalizatórias, e de natureza investigatória.
} 
por ser um procedimento mais simplificado e direto, realizado independentemente de intervenção diplomática e de tramitação por tribunais superiores. É iniciado por solicitação do ente estrangeiro ao juiz nacional, ora se perfectibilizando diretamente entre os órgãos judiciários, ora sendo intermediado por autoridades centrais.

Na síntese de Loula (2010), o auxílio direto constitui um mecanismo facilitador da cooperação jurídica internacional, dispensando o juízo de delibação, evitando a coexistência de múltiplas jurisdições e reduzindo a complexidade das comunicações.

No Brasil, o auxílio direto ainda é pouco utilizado, tendo aplicação subsidiária aos instrumentos tradicionais de cooperação. É aplicável por exclusão, ou seja, quando as providências pretendidas não abrangerem a homologação de sentenças e laudos arbitrais estrangeiros ou a concessão de exequatur às cartas rogatórias.

\subsection{Fundamentos do Auxílio Direto em Matéria Cível no Ordenamento Jurídico Brasileiro}

No sistema constitucional brasileiro, o tema de cooperação judicial foi tratado de forma esparsa e genérica. $\mathrm{O}$ artigo $4^{\circ}$ da Constituição arrola os princípios que regem as relações internacionais da República brasileira, inserindo dentre eles, no inciso IX, o princípio da cooperação entre os povos para o progresso da humanidade.

Outros dispositivos constitucionais reforçam o princípio de cooperação. O parágrafo único do art. $4^{\mathrm{o} 3}$ prevê a formação de uma comunidade latinoamericana de nações, mediante a busca da integração econômica, política, social e cultural entre os povos da América Latina. Ainda que, como refere Abade, a doutrina e o entendimento jurisprudencial a respeito da questão não vislumbrem nesse dispositivo constitucional fundamento bastante para tratar de forma privilegiada a cooperação com os demais países da América Latina (ABADE, 2013), fato é que, ao menos em linha de princípio, a integração é um imperativo constitucional.

Refira-se também a disposição inserta no artigo 181 da Constituição, que trata do atendimento de requisição de documento ou informação comercial

3 "Parágrafo único. A República Federativa do Brasil buscará a integração econômica, política, social e cultural dos povos da América Latina, visando à formação de uma comunidade latino-americana de nações". 
feita por autoridade judiciária ou administrativa estrangeira. Ainda que a previsão seja de aplicação limitada às questões de natureza comercial, constitui mais um elemento que reforça o princípio geral de cooperação.

Prevendo competências específicas a respeito da cooperação, refiramse também as disposições insertas no artigo 102, I, 'g', que prevê a competência do Supremo Tribunal Federal para exame dos pedidos de extradição e no artigo 105, I, 'i', na redação da EC 45, que estabelece a competência do STJ para processar e julgar a homologação de sentenças estrangeiras e conceder exequatur às cartas rogatórias.

Saliente-se que tais disposições não impedem outras formas de cooperação, constituindo apenas regra de competência quanto aos mecanismos ali determinados. Daí não decorre que haja vedação a outras formas de cooperação judiciária internacional em outros órgãos jurisdicionais, nem há exigência de que seja concentrada nos tribunais superiores a competência para o processamento de todos os pedidos de cooperação.

Em que pesem as previsões constitucionais e a multiplicidade de acordos internacionais, a regulamentação da cooperação judiciária, no plano do ordenamento interno brasileiro, ainda é insuficiente. O sistema jurídico brasileiro, conforme Abade (2013), padece de um modelo de incidência que compreenda todas as modalidades de cooperação jurídica internacional, sendo essa lacuna legislativa evidenciada especialmente em relação ao auxílio direto, ausente do ordenamento jurídico interno ${ }^{4}$.

Não se quer dizer com isso que haja inaplicabilidade dos institutos de cooperação internacional: à falta da legislação específica, o delineamento do tema se fundamenta nos tratados e convenções internacionais que preveem formas de cooperação judiciária em auxílio direto.

No sistema jurídico brasileiro, os acordos e convenções incorporados ao direito interno brasileiro adquirem força de lei, ou inclusive, nos casos previstos na EC 45/2004, são equiparados a normas constitucionais. A respeito do tema,

\footnotetext{
${ }^{4}$ Saliente-se que tramitavam no Congresso Nacional anteprojetos de lei de cooperação judiciária internacional buscando suprir o vazio legislativo, elaborados pela Associação dos Juízes Federais do Brasil (AJUFE), pela Escola Superior do Ministério Público da União (ESMPU) e pelo Ministério da Justiça. O projeto de novo Código de Processo Civil (Projeto de Lei 8046/2010), em tramitação no Senado brasileiro, originado de um anteprojeto redigido por uma comissão de juristas. O projeto amplia o arcabouço normativo existente em relação à cooperação jurídica internacional, contendo um capítulo específico sobre o tema da cooperação internacional, compreendendo os artigos 25 a 41. O auxílio direto é tratado na Seção III, a partir do artigo 34, disciplinando a competência, o papel da autoridade central e o procedimento. O texto do anteprojeto representa uma grande evolução em relação ao tema, suprindo a lacuna legislativa atualmente existente e que embaraça a correta aplicação do mecanismo.
} 
confira-se o seguinte julgado do Supremo Tribunal Federal, o qual, ainda que referente especificamente a um desses instrumentos, bem demonstra o entendimento no sentido da necessidade de observância dos tratados internacionais acerca da cooperação judiciária:

A primeira observação a ser feita, portanto, é a de que estamos diante de um documento produzido no contexto de negociações multilaterais a que o País formalmente aderiu e ratificou. Tais documentos, em que se incluem os tratados, as convenções e os acordos, pressupõem o cumprimento de boafé pelos Estados signatários. É o que expressa o velho brocardo Pacta sunt servanda. A observância dessa prescrição é o que permite a coexistência e a cooperação entre nações soberanas cujos interesses nem sempre são coincidentes. [...] a Convenção é compromisso internacional do Estado brasileiro em plena vigência e sua observância se impõe. (BRASIL, 2009.)

Admitida a constitucionalidade formal do auxílio direto, surge a questão da constitucionalidade material, ou seja, do atendimento das exigências constitucionais materiais. Como o auxílio direito, tal como concebido no sistema jurídico brasileiro, efetiva-se por meio de um processo judicial interno, segue os mesmos ditames aplicáveis a estes, devendo, como qualquer outro, observar as garantias constitucionais, dentre as quais a ampla defesa, o contraditório e o devido processo legal, bem como as normas de direito interno. Como assinala Zavascki, "Outra característica importante desse sistema padronizado de cooperação jurídica é a do estrito respeito às normas de direito interno de cada Estado Parte, o que inclui cláusula de recusa à assistência quando o pedido for incompatível com essas normas" (ZAVASCKI, 2010).

O auxílio direto tem como requisito a existência de acordo de cooperação jurídica internacional bilateral ou multilateral, ou quando houver a promessa de reciprocidade por parte do requerente. O Brasil é signatário de vários tratados e acordos internacionais que prevêem modalidades de cooperação que podem ser identificadas como auxílio direto, ou assistência direta, ainda que não tenham sido assim denominadas.

No âmbito da Conferência de Direito Internacional Privado da Haia, o Brasil é signatário ${ }^{5}$ de vários acordos internacionais multilaterais que incluem

\footnotetext{
${ }^{5}$ Encontram-se em procedimento de internalização, ainda não tendo sido objetos de ratificação pelo Brasil, os seguintes pactos: Convenção relativa à Citação e Notificação no estrangeiro dos Atos Judiciais e Extrajudiciais em Matéria Civil e Comercial; Convenção relativa à Supressão da Exigência da Legalização de Documentos Públicos Estrangeiros e a Convenção sobre acordos de eleição de foro.
} 
modalidades de cooperação judicial em processo civil, sejam específicas sobre temas processuais ${ }^{6}$ sejam acordos gerais sobre determinados temas considerados especialmente sensíveis; um dos acordos da Haia interessa especialmente a este trabalho, qual seja, a Convenção sobre os Aspectos Civis do Sequestro Internacional de Crianças, firmada em 1980, cujo procedimento no Brasil e na Colômbia será objeto de exame mais adiante. ${ }^{7}$ Também no âmbito do continente americano há uma multiplicidade de tratados prevendo a cooperação judicial ${ }^{8}$.

No âmbito regional, o Brasil é signatário do Mercado Comum do Sul (MERCOSUL), criado no Tratado de Assunção de $1991^{9}$, que em vários de seus instrumentos encerra previsão de instrumentos de cooperação judicial entre os países integrantes. Para constar, refira-se ainda que o país é signatário de numerosos acordos bilaterais ${ }^{10}$.

${ }^{6}$ Convenção sobre Acesso Internacional à Justiça (aprovada pelo Dec. Legislativo 658/2010), e a Convenção sobre a Obtenção de Provas no Estrangeiro em Matéria Civil ou Comercial, 1970 (aprovada recentemente, com ressalva, pelo Decreto-Legislativo 137, de 19.02.2013)

7 A Convenção sobre os Aspectos Civis do Sequestro Internacional de Crianças e a Convenção relativa à Proteção das Crianças e à Cooperação em Matéria de Adoção Internacional, ambas firmadas pelo Brasil, também contêm dispositivos prevendo formas de assistência judiciária.

${ }^{8}$ Refira-se, dentre outras: Convenção de Nova Iorque. Convenção sobre Prestação de Alimentos no Estrangeiro. (Decreto n. 56.826, de 02/09/1965); Convenção Interamericana sobre Cartas Rogatórias, em matéria civil ou comercial. (Decreto n. 1.899, de 09/05/1996); Convenção Interamericana sobre Regime Legal das Procurações para serem Utilizadas no Exterior. (Decreto 1.213, de 03/08/ 1994); Convenção Interamericana sobre Prova e Informação Acerca do Direito Estrangeiro (Decreto 1.925, de 10/06/1996); Convenção Interamericana sobre Eficácia Extraterritorial das Sentenças e Laudos Arbitrais Estrangeiros, proferidos em processos civis, comerciais ou trabalhistas. Decreto n. 2.411, de 02/12/1997; Convenção Interamericana sobre Obrigação Alimentar (IV CIDIP). Decreto n. 2.428, de 17/12/1997; Convenção Interamericana sobre Tráfico Internacional de Menores. Decreto n. 2.740, de 20/08/1998

9 Tratado para a Constituição de um Mercado Comum entre a República Argentina, a República Federativa do Brasil, a República do Paraguai e a República Oriental do Uruguai. Disponível na internet: http://www.mercosul.gov.br/normativa/tratados-e-protocolos/tratado-de-assuncao-1/.

${ }^{10}$ Dentre os acordos e tratados bilaterais firmados pelo Brasil prevendo a cooperação judiciária em matéria cível, pode-se citar: o Convênio de Cooperação Judiciária em Matéria Civil entre o Governo da República Federativa do Brasil e o Reino da Espanha (Decreto no 166,de 3 de julho de 1991); o Acordo sobre Cooperação Judiciária em Matéria Civil entre o Governo da República Federativa do Brasil e o Governo da República Libanesa (Decreto no 7934, de 19 de fevereiro de 2013); o Acordo sobre Cooperação em Matéria Civil entre o Governo da República Federativa do Brasil e o Governo da República Francesa (Decreto $n^{\circ} 3598$, de 12 de setembro de 2000); o Acordo de Cooperação Judiciária em Matéria Civil, Comercial, Trabalhista e Administrativa, entre o Governo da República Federativa do Brasil e o Governo da República Oriental do Uruguai (Decreto n 1850, de 10 de abril de 1996); o Acordo de Cooperação Judiciária em Matéria Civil, Comercial, Trabalhista e Administrativa, entre o Governo da República Federativa do Brasil e o Governo da República Argentina (Decreto ${ }^{\circ} 1560$, de 18 de julho de 1995) e o Tratado relativo à Cooperação Judiciária e ao Reconhecimento de sentenças em Matéria Civil entre a República Federativa do Brasil e a República Italiana (Decreto $\mathrm{n}^{\circ}$ 1476, de 2 de maio de 1995). 
No entanto, em que pesem a inserção do princípio da cooperação no texto constitucional e a multiplicidade de tratados sobre o tema, não há entre os operadores uma difusão ampla a respeito da prática da cooperação. Os mecanismos de cooperação são limitados, e ademais os entendimentos jurisprudenciais tendem a ser restritivos sobre o tema, o que Abade reputa ser devido a um choque entre os paradigmas da soberania e da cooperação interessada frente aos princípios do reconhecimento recíproco, da solidariedade e da confiança. (ABADE, 2013)

O problema se agrava no caso do auxílio direto, que é o mecanismo menos difundido. Ainda que a inexistência de legislação específica não impeça o uso do mecanismo, dificulta a sua efetivação prática, pelo desconhecimento dos operadores acerca do conteúdo, alcance e hipóteses do auxílio direto.

Em suma, a efetividade da cooperação demanda conformação dos sistemas jurídicos e dos textos normativos, bem como a instituição de práticas administrativas e mecanismos jurisdicionais adequados. No tópico que segue, serão examinados a competência e o procedimento do auxílio direto no sistema jurídico brasileiro.

\subsection{Competência e Procedimento}

Ainda que se concebam, como referido na primeira parte deste tópico, múltiplas formas de auxílio direto, para os fins deste trabalho examina-se o instituto tal como atualmente adotado no Brasil, o qual se viabiliza por procedimentos realizados no âmbito do Poder Executivo e do Poder Judiciário, e é efetivado por intermédio de autoridades centrais, a quem compete dar o encaminhamento adequado às solicitações de auxílio, seja pela via administrativa, seja pela via judicial.

Conforme definição constante no site do Ministério da Justiça,

O auxílio direto diferencia-se dos demais mecanismos porque nele não há exercício de juízo de delibação pelo Estado requerido. Não existe delibação porque não há ato jurisdicional a ser delibado. Por meio do auxílio direto, o Estado abre mão do poder de dizer o direito sobre determinado objeto de cognição para transferir às autoridades do outro Estado essa tarefa. Não se pede, portanto, que se execute uma decisão sua, mas que se profira ato jurisdicional referente a uma determinada questão de mérito que advém de litígio em curso no seu território, ou mesmo que se obtenha ato administrativo a colaborar com o exercício de sua cognição. Não há, por conseqüência, o exercício de jurisdição pelos dois Estados, mas apenas pelas autoridades do Estado requerido. 
Podem ser objeto de auxílio direto a comunicação de atos processuais (citações, intimações e notificações), a obtenção de provas e, em certas hipóteses, a obtenção de medidas cautelares e de decisões de tutela antecipada. Tratados específicos trazem algumas medidas específicas que podem ser obtidas por esse mecanismo. É o caso, por exemplo, das decisões de busca, apreensão e retorno de crianças ilicitamente subtraídas do convívio de um dos pais, nos termos da Convenção sobre os Aspectos Civis do Sequestro Internacional de Crianças (BRASIL, 2000).

A natureza do ato solicitado determina a espécie de cooperação. Como refere Loula (2010), se, por exemplo, é solicitada informação sobre o andamento de processo, constitui mera cooperação administrativa; se a solicitação é de prática de ato que no país onde será efetivado deve ser praticado pelo Poder Judiciário, trata-se de cooperação jurídica.

Considerada a multiplicidade de medidas que podem ser solicitadas, fazse necessário determinar um critério para o procedimento. A respeito, assevera Zavascki que o pedido de auxílio direto deve seguir os mesmos procedimentos usados para medidas semelhantes no âmbito interno:

$\mathrm{O}$ atendimento das providências de cooperação dessa natureza deve seguir os mesmos padrões, inclusive processuais, que devem ser observados para as providências semelhantes no âmbito interno. Caso seja necessária prévia autorização judicial, cabe aos agentes do Estado requerido atuarem judicialmente visando obter a autorização (ZAVASCKI, 2010, p. 12).

Em síntese, se as providências solicitadas no pedido de auxílio direto exigirem, de acordo com a legislação brasileira, decisão judicial, a autoridade competente deve tomar as providências a respeito, propondo perante a justiça brasileira as ações que se fizerem necessárias.

Inexistindo lei regulamentadora do procedimento, aplica-se a Resolução $n^{\circ}$ 9/2005 do Superior Tribunal de Justiça, que dispôs sobre o auxílio direto no parágrafo único do art. $7^{\circ}$, nos seguintes termos:

Art. $7^{\circ}$ As cartas rogatórias podem ter por objeto atos decisórios ou não decisórios.

Parágrafo único. Os pedidos de cooperação jurídica internacional que tiverem por objeto atos que não ensejem juízo de delibação pelo Superior Tribunal de Justiça, ainda que denominados como carta rogatória, serão encaminhados ou devolvidos ao Ministério da Justiça para as providências necessárias ao cumprimento por auxílio direto (BRASIL, 2005). 
Os pedidos de cooperação internacional pela via do auxílio direto devem ser dirigidos à autoridade central, em substituição à via consular, seguindo o mecanismo criado na Convenção de Haia, previsto pela primeira vez no Tratado sobre transmissão de atos processuais, em 1965. Cabe à autoridade central o encaminhamento das solicitações, adotando as providências que se fizerem necessárias para tanto, inclusive quanto à adequada instrução dos pedidos.

De regra, se não houver previsão específica indicando outra autoridade central, a atribuição compete ao Ministério da Justiça, que o exerce por intermédio do Departamento de Recuperação de Ativos e Cooperação Jurídica Internacional (DRCI) no âmbito da Secretaria Nacional de Justiça. A respeito, estabelece o inciso IV do art. 11 do Decreto 6061/2007:

Art. 11. Ao Departamento de Recuperação de Ativos e Cooperação Jurídica Internacional compete:

$[\ldots]$

IV - exercer a função de autoridade central para tramitação de pedidos de cooperação jurídica internacional (BRASIL, 2007).

A defesa judicial no auxílio direto cível cabe, em princípio, à Advocacia Geral da União, em matéria civil.

A competência para os processos judiciais que veiculem o pedido de auxílio direto é da Justiça Federal de primeira instância, a quem incumbe, em nosso sistema, na forma do art. 109, I, da Constituição da República, o processo e julgamento dos feitos nos quais tenham interesse órgãos públicos federais, bem como, com base no art. 109, III, julgar as causas fundadas em tratados (TIBURCIO, 2005).

A autoridade estrangeira pode participar nos atos praticados perante o juízo brasileiro. Contudo, essa participação somente é admitida de forma passiva, não se admitindo a prática de atos de jurisdição pela autoridade estrangeira no Brasil. A jurisprudência do Supremo Tribunal Federal já assentou que "No plano da cooperação internacional, é possível a participação das autoridades estrangeiras, desde que não haja nenhuma interferência delas no curso das providências tomadas". ${ }^{11}$

No Brasil, na praxe administrativa e judiciária, uma das aplicações mais frequentes da cooperação pela via do auxílio direto ocorre nos casos de combate

${ }^{11}$ HC 89.171, Rel. p/ o ac. Min. Menezes Direito, julgamento em 24-3-2009, Primeira Turma, DJE de 8-5-2009. 
ao sequestro internacional de menores, com base na Convenção da Haia sobre os Aspectos Civis do Sequestro Internacional de Crianças, de 1980, da qual também é signatária a Colômbia. No tópico que segue, serão analisados os procedimentos adotados no Brasil e na Colômbia, buscando traçar uma análise comparativa das formas de efetivação da cooperação jurídica internacional de ambos os países em relação ao tema do sequestro interparental.

\section{ANÁliSE COMPARATIVA DO PROCEDIMENTO DE AUXÍLIO DIRETO CIVIL NOSEQUESTRO INTERNACIONAL DE MENORES NOS SISTEMAS BRASILEIRO E COLOMBIANO}

Antes de avaliar o trato procedimental dos pedidos de restituição de menores nos casos de subtração internacional de menores, ou sequestro internacional de menores ${ }^{12}$, cabe traçar, para melhor compreensão do tema, uma breve contextualização acerca da questão.

A subtração indevida ocorre quando uma criança ou adolescente é retirada de sua residência habitual, na qual se encontra sob a proteção de uma pessoa que detém a sua guarda legítima. Tais situações já são bastante delicadas no âmbito do território estatal, mas o problema se agrava quando se trata de deslocamento da criança para o território de outro país, não submetido à jurisdição do Estado no qual a criança tinha residência. Como proceder em relação aos conflitos causados por genitores que transferem os filhos para outros países que não os de sua residência habitual, subtraindo a guarda dos filhos ao outro genitor?

A questão há muito tempo preocupa a comunidade internacional. $\mathrm{Na}$ busca de uma solução mais adequada a esses conflitos, foi celebrada a Convenção da Haia sobre os Aspectos Civis do Sequestro Internacional de Crianças de 1980, que entrou em vigor no plano internacional em $1983^{13}$. A Convenção pode ser aplicada para repatriação de todos os menores até 16

\footnotetext{
${ }^{12}$ A expressão "sequestro internacional de crianças" adotada no Brasil não é mais adequada. Como refere Maurique, o ato combatido não constitui sequestro criminal "tal como conhecemos no Direito Penal. Trata-se, isto sim, de (a) um deslocamento ilegal da criança de seu país de residência habitual e/ou (b) uma retenção indevida da criança em outro país que não a residência habitual. Nos países de língua inglesa, o termo empregado é "abdução" (abduction), e não "sequestro". Já nos países francófonos, o termo utilizado é "retirada" ou "remoção" (enlèvement)" (MAURIQUE, 2009).

${ }^{13}$ Refira-se que há outros pactos internacionais sobre o tema da subtração de menores, dentre os quais a Convenção Interamericana sobre Restituição Internacional de Menores (Cirim) celebrada em Montevidéu em 1989.
} 
anos que, quando do ato de subtração tido por ilegítimo, mantivessem residência habitual em um dos Estados contratantes (VERA, 1982).

O objetivo da Convenção é garantir o retorno imediato dos menores trasladados ou retidos de forma ilícita, evitando que sejam subtraídos ao ambiente familiar e social no qual se desenvolviam (VERA, 1982), permitindo que as questões sobre a guarda sejam decididas no foro competente para tanto, perante o país de residência habitual da criança.

A Convenção tem mais de 80 países signatários, dentre os quais a Colômbia e o Brasil. Na Colômbia, a Convenção foi aprovada pela Lei 173/94; no Brasil, a internalização ocorreu pelo Decreto Legislativo n. 79, de 12 de junho de 1999, e a ratificação ocorreu apenas quando da promulgação do Decreto n. 3.413/ 2000, tendo entrado em vigor em 14 de abril do mesmo ano.

No ponto que aqui interessa desenvolver, a Convenção estabelece um procedimento sumário e célere para a tramitação dos pedidos de restituição dos menores. Dentro da proposta deste trabalho, cabe avaliar se os sistemas colombiano e brasileiro têm oferecido mecanismos administrativos e judiciais internos que assegurem a proteção adequada dos interesses dos menores indevidamente subtraídos ou retidos.

Na Colômbia, a Lei 1008 de 2006 (REPÚBLICA DE COLÔMBIA, 2006a) fixou a competência e o procedimento para a aplicação dos convênios internacionais a respeito da menoridade e de família, complementada a seguir pelo Código de la infancia y la adolescencia (REPÚBLICA DE COLÔMBIA, 2006b). Assim, supriram o vazio legislativo, internalizando os ditames da Convenção da Haia, e estabelecendo o procedimento para o encaminhamento dos pedidos de auxílio. No Brasil, ausente lei interna específica, aplicam-se diretamente o texto da Convenção e as normatizações administrativas sobre o tema ${ }^{14}$.

A autoridade central no Brasil para encaminhamento dos procedimentos baseados na Convenção da Haia sobre os Aspectos Civis do Sequestro Internacional de Crianças é a Secretaria de Direitos Humanos da Presidência da República (Dec. 3951/2001) ${ }^{15}$.

Em ambos os países, na linha da Convenção da Haia, o procedimento prevê duas fases, uma fase judicial e outra administrativa.

\footnotetext{
${ }^{14}$ Dentre os quais, a já referida Resolução no 9/2005 do Superior Tribunal de Justiça; a Portaria Interministerial no 501/2012/MJ/MRE; o Decreto 6061/2007; o Decreto 3951/2001.

${ }^{15}$ Perante o Supremo Tribunal Federal brasileiro, funciona um grupo permanente de trabalho sobre a Convenção de Haia, bem como foram nomeados dois juízes de ligação, buscando formas de aprimorar a aplicação da Convenção no território brasileiro. A respeito, ver Sifuentes (2009).
} 
A primeira fase ocorre na via administrativa, para a tentativa de composição amigável dos litígios. Na Colômbia, é realizada pelos funcionários das Comissárias de Família ou do Instituto Colombiano de Bienestar Familiar (ICBF). No Brasil, as tratativas de conciliação estão ao encargo da Secretaria de Direitos Humanos da Presidência da República.

$\mathrm{Na}$ inviabilidade de acordo, a segunda fase se dá pela via judicial, sendo requerida a medida judicial perante a respectiva justiça nacional. Saliente-se que, tanto na Colômbia quanto no Brasil, não se admite a restituição do menor sem a autorização judicial prévia, porque se tratam de medidas que nos respectivos direitos internos só podem ser determinadas pelo Poder Judiciário.

Na Colômbia, nos termos da Ley 1008 de 2006 e do Código de la infancia y la adolescencia (REPÚBLICA DE COLÔMBIA, 2006b), o rito a ser seguido é o do 'proceso verbal sumario', que está previsto no artículo $435,5^{\circ}$, do Código de Processo Civil colombiano ${ }^{16}$. No Brasil, não há normatização de um rito específico.

A legitimidade da propositura da ação judicial no Brasil compete à Advocacia-Geral da União, que representa os interesses da União em juízo ${ }^{17}$. Na Colômbia, cabe aos Defensores de Família solicitar a providência judicial, informando ao juiz sobre a não realização de acordo entre os interessados.

A competência para o processo e julgamento da ação judicial no Brasil, pelas razões já aduzidas em outra parte deste trabalho, pertence à Justiça Federal. Na Colômbia, o processo e julgamento se inserem na competência dos Juízes de Família ou 'Promíscuos de Família' (SANTACRUZ-LOPEZ, 2007).

De todo o exposto, verifica-se que tanto o Brasil quanto a Colômbia adotaram praxes administrativas e judiciais buscando adequar-se e conformarse à Convenção da Haia, criando mecanismos para buscar oferecer proteção adequada aos interesses do menor.

Entretanto, enquanto a Colômbia introduziu em seu sistema um procedimento sumário para tratar do tema, no Brasil, a ausência de previsão específica remete à utilização do rito ordinário.

Neste particular, e diante da relevância do caso, exige-se maior celeridade na tramitação dos procedimentos, o que faz parecer que no Brasil, embora tenha havido a preocupação em se estabelecer em linhas gerais o auxílio direto

\footnotetext{
${ }^{16}$ Neste particular, conforme Blanco-Rodriguez e Santacruz-Lopez, o legislador incorporou a jurisprudência da Corte Constitucional colombiana, expressa na Sentencia T-831 de 2003, magistrado ponente: Rodrigo Escobar Gil. (BLANCO-RODRIGUEZ; SANTACRUZ-LOPEZ, 2009).

${ }^{17}$ A respeito, ver a cartilha elaborada pela Advocacia-Geral da União (BRASIL, 2011).
} 
para combater o sequestro internacional de menores, faltou completar o ciclo com previsão de um procedimento mais célere, tal como o tema exige.

\section{CONSIDERAÇÕES FINAIS}

Em tempos de crise do Estado e do Direito, um dos problemas que mais aflige as sociedades modernas é o tema da garantia da efetividade dos direitos. A jurisdição prestada em tempo razoável, como instrumento para garantia dos direitos e garantias fundamentais, constitui-se também um direitogarantia. Como assegurar uma tutela dos direitos fundamentais nas relações sociais globalizadas e sem fronteiras, frente a concepções de Direito, de processo e de jurisdição calcadas na soberania estatal?

Torna-se necessário pensar em formas de interação cooperativa ente os diferentes ordenamentos jurídicos, sem que com isso se afete os limites da soberania dos Estados. Os sistemas processuais devem adaptar-se para dar solução a esse novo padrão de controvérsias multilocalizadas, não restritas ao espaço estatal, garantindo a concretização dos direitos, a segurança jurídica e a isonomia na aplicação da lei também nas lides com conotações plurinacionais.

Nesse contexto, a cooperação judicial é um imperativo da própria garantia da soberania estatal, da consolidação dos regimes democráticos e da efetivação dos direitos fundamentais, não se tratando de mero ato de cortesia ou de simples conveniência.Os instrumentos cooperativos constituem um imperativo de preservação da própria soberania, que, ameaçada pela complexidade das relações jurídicas na sociedade contemporânea, não mais se sustenta em condições de exclusão e isolamento.

A reconcepção do processo civil, em molde cooperativo, implica o aparelhamento dos sistemas nacionais, a harmonização dos sistemas jurídicos, a conformação dos textos legais e a adequação das práticas judiciais e administrativas.

O auxílio direito, novo instrumento previsto em tratados e acordos bilaterais, regionais ou múltiplos, constitui um mecanismo mais célere e informal, que dispensa juízo de delibação e intervenção diplomática.

A condição de admissibilidade do auxílio direto é de que o pedido se fundamente em tratados internacionais ou, na inexistência destes, na garantia de reciprocidade, sendo necessário também que sejam observadas as garantias constitucionais do devido processo legal, contraditório e ampla defesa. 
Conceber uma atuação jurisdicional cooperativa no plano internacional não constitui por si só um novo modelo, nem representa solução para todos os dilemas da globalização. Mas é uma forma de colaborar na superação da fratura entre o mundo globalizado e o Estado-Nação, na construção de um Estado integrado e cooperativo no plano internacional.

Uma das aplicações mais importantes do auxílio direto como forma de cooperação judiciária ocorre no caso do sequestro interparental internacional, no qual um menor é subtraído de sua residência habitual em que se encontra sob guarda legítima. O tema foi objeto de pacto na Convenção da Haia, firmado pelo Brasil e pela Colômbia, entre outros partícipes, prevendo procedimento sumário e célere para a tramitação dos pedidos de restituição.

Constata-se que os procedimentos adotados no Brasil e na Colômbia são bastante semelhantes. Ambos os países buscaram instituir procedimentos internos conformes aos termos da Convenção, com adaptação das respectivas normatizações em nível legal ou infralegal, bem como praxes administrativas específicas e mecanismos judiciais adequados.

Dentre as principais distinções entre os sistemas dos dois países, o fato de que a Colômbia estabeleceu um procedimento específico em lei e no Código da Criança e do Adolescente, bem como previu a concentração da competência dos feitos, temas que ainda constituem pontos frágeis no sistema brasileiro.

\section{REFERÊNCIAS}

ABADE, Denise Neves. Direitos fundamentais na cooperação jurídica internacional: extradição, assistência jurídica, execução de sentença estrangeira e transferência de presos. São Paulo: Saraiva, 2013.

ALLARD, Julie; GARAPON, Antoine. Os juízes na mundialização: a nova revolução do direito. Tradução de Rogério Alves. Lisboa: Instituto Piaget, 2005.

BLANCO-RODRIGUEZ, Jyniola; SANTACRUZ-LOPEZ, Raul. La restitución internacional de menores sustraidos por suspropios padres. Estudios Socio-Jurídicos, Bagotá, v. 11, n. 2, p. 229 - 255, jul./dec. 2009. Disponível em: $<$ http://revistas.urosario.edu.co/index.php/ sociojuridicos/ article/view/429/567>. Acesso em: 28 jun. 2014. 
BRASIL. Advocacia-Geral da União. Procuradoria-Geral da União.

Combate à subtração internacional de crianças: a Convenção da Haia sobre os aspectos civis do sequestro internacional de crianças. Brasília: AGU/PGU, 2011.

. Decreto $\mathbf{n}^{\mathbf{0}}$ 3.423, de 14 de abril de 2000. Promulga a Convenção sobre os Aspectos Civis do Seqüestro Internacional de Crianças, concluída na cidade de Haia, em 25 de outubro de 1980. Disponível em: <http://www.planalto.gov.br/ccivil_03/decreto/D3413.htm>.Acesso em: 28 jun. 2014.

. Decreto $\mathbf{n}^{\circ}$ 6.061, de 15 de março de 2007. Aprova a Estrutura Regimental e o Quadro Demonstrativo dos Cargos em Comissão e das Funções Gratificadas do Ministério da Justiça, e dá outras providências. Disponível em: <http://www2.camara.leg.br/legin/ fed/decret/2007/decreto6061-15-marco-2007-552133-normaatualizada-pe.html >. Acesso em: 28 jun. 2014.

BRASIL. Superior Tribunal de Justiça. Resolução $\mathbf{n}^{\mathbf{0}}$ 9, de 4 de maio de 2005. Dispõe, em caráter transitório, sobre competência acrescida ao Superior Tribunal de Justiça pela Emenda Constitucional no 45/2004. Disponível em: <http://www.stj.jus.br/webstj/Institucional/Biblioteca/Clipping/ 2Imprimir2.asp?seq_edicao $=844 \&$ seq_materia $=10529>$. Acesso em: 28 jun. 2014.

. Supremo Tribunal Federal. ADPF 172-MC-REF, Relator Ministro Marco Aurélio, trecho de voto da Ministra Ellen Gracie Northfleet, julgamento em 10 jun. 2009, Plenário, Diário da Justiça Eletrônico, São Paulo, ano 2, n. 539, 21 ago. 2009.

CHEVALLIER, Jacques. O estado de direito. Tradução de Antônio Ataldo Ferraz Dal Pozzo. Belo Horizonte: Fórum, 2013.

DELMAS-MARTY, Mireille. Résister, responsabiliser, anticiper ou comment humaniser la mondialisation. Paris: Seuil, 2013.

DIDIER JUNIOR, Fredie. Teoria do processo e teoria do direito: o 
neoprocessualismo. In: . (Org.). Teoria do processo: panorama doutrinário mundial. Salvador: JusPodivm, 2010. p. 257-264.

FACCHINI NETO, Eugênio. O Judiciário no mundo contemporâneo. In: MOLINARO, Carlos Alberto; MILHORANZA, Mariângela Guerreiro; PORTO, Sérgio Gilberto. Constituição, jurisdição e processo. Porto Alegre: Notadez, 2007. p. 297-328.

GAMA JUNIOR, Lauro. Contratos internacionais à luz dos princípios do UNIDROIT 2004. Rio de Janeiro: Renovar, 2006.

GIDDENS, Anthony. As conseqüências da modernidade. São Paulo: Unesp, 1991.

HÄBERLE, Peter. Estado constitucional cooperativo. Tradução de Marcos Augusto Maliska e Elisete Antoniuk. Rio de Janeiro: Renovar, 2007.

LANDO, Ole. The law applicable to the merits of the dispute. In: SARCEVIC (Ed.). Essays on international commercial arbitration. London: Martinus Nijhoff, 1991.p. 129-159. Disponível em: <http: tldb.unikoeln.de>. Acesso em: 30 maio 2014.

LOULA, Maria Rosa Guimarães. Auxílio direto: novo instrumento de cooperação jurídica internacional civil. Belo Horizonte: Fórum, 2010.

LUHMANN, Niklas. Globalizationor world society: how to conceive of modern society? International Review of Sociology, Roma, v. 7, n. 1, p. 67-80, 1997.

MARINONI, Luiz Guilherme; ARENHART, Sérgio Cruz. Processo de conhecimento. 12. ed. São Paulo: RT, 2014.

MAURIQUE, Jorge Antonio. Anotações sobre a convenção de Haia. Revista de Doutrina da $4^{\mathbf{a}}$ Região, Porto alegre, n. 28, mar. 2009. Disponível em <http://www.revistadoutrina.trf4.jus.br/artigos/edicao028/ jorge_maurique.html>. Acesso em: 28 jun. 2014. 
REPÚBliCA DE COLOMBIA. Congreso Nacional. Ley 1008 de 23 de janeiro de 2006a. Por la cual se fijan algunas competencias y procedimientos para la aplicación de convenios internacionales en materia de niñez y de familia. Disponível em: $<$ http://www.oas.org/ dil/esp/ Ley_1008_de_2006_Colombia.pdf>. Acesso em: 28 jun. 2014.

\section{. Congreso Nacional. Ley 10988 de noviembre de 2006b.}

Código de laInfancia y la Adolescencia. Disponível em: <http:// www.procuraduria.gov.co/portal/media/file/ Visi\%C3\%B3n\%20Mundial_Codigo\%20de\%20Infancia\%202011(1).pdf〉. Acesso em: 28 jun. 2014.

SANTACRUZ-LOPEZ, Raul. Sobre lanecesidad de establecer un procedimiento preferente y sumario para eltrámite de los conflictos generados por la sustracción interparental de menores. Avances y resultados de investigación In: ENCUENTRO DE LA RED DE GRUPOS Y CENTROS DE INVESTIGACIÓN JURÍDICA Y SOCIOJURÍDICA, 7., 2007, Medellín. Anales... Medellín: Universidad Pontificia Bolivariana, 2007. p. 177-187. Disponível em: <http://www.redsociojuridica.org/ Memorias_VII_Encuentro_de_la_Red_Sociojuridica.pdf $>$. Acesso em: 28 jun. 2014.

SIFUENTES, Monica. Sequestro interparental: a experiência brasileira na aplicação da Convenção da Haia de 1980. Revista da SJRJ, Rio de Janeiro, n. 25, p. 135-144, 2009. Disponível em: <http://www4.jfrj.jus.br/seer/ index.php/revista_sjrj/article/viewFile/9/9>. Acesso em: 28 jun. 2014.

SLAUGHTER, Anne-Marie. A tipology of transjuditial communication. University of Richmond Law Review, Virginia, v. 29, p. 99-137, 1994. Disponível em: <http://www.princeton.edu/ slaughtr/Articles/Typology.pdf〉. Acesso em: 1 abr. 2014.

TEIXEIRA, Anderson Vichinkeski. Teoria pluriversalista do direito internacional. São Paulo: WMF Martins Fontes, 2011.

TIBURCIO, Carmen. A dispensa de rogatória no atendimento de solicitações provenientes do exterior. Revista de Processo, São Paulo, v. 30, n. 126, p. 115-118, ago. 2005. 
VERA, Elisa Pérez. Rapport explicatif surla Convention de La Haye de 1980 surl'enlèvement international d'enfants. Publications de la HCCH, p. 426476, 1982. Disponível em: 〈http://www.hcch.net/upload/expl28.pdf〉. Acesso em: 28 jun. 2014.

ZAVASCKI, Teori Albino. Cooperação jurídica internacional e a concessão de exequatur. Revista de Processo, Belo Horizonte, v. 35, n. 183, p. 9-24, maio. 2010.

Recebido em: 24/09/2014 Aprovado para publicação em: 31/03/2015

Como citar: MIZUTA, Alessandra. HENDGES, Carla Evelise Justino. Cooperação judicial internacional no combate à subtração internacional de menores no Brasil e na Colômbia. Revista do Direito Público. Londrina, v.10, n.1, p.99-126, jan./abr.2015. DOI: 10.5433/1980511X.2015v10n1p99. 